\title{
S8 Appendix
}

Sagittal otolith preparations for representative stage 4 individuals of four rarer species of Brachyhypopomus. Dotted lines are superimposed to highlight the positions of the otolith core and dark annuli. Note the single dark annulus in B. benjamini, B. flavipomus, and B. regani. Note the single dark annulus in a putative $0+$ year group of $B$. brevirostris, but two dark annuli in a putative $1+$ year group.

\section{B. benjamini}

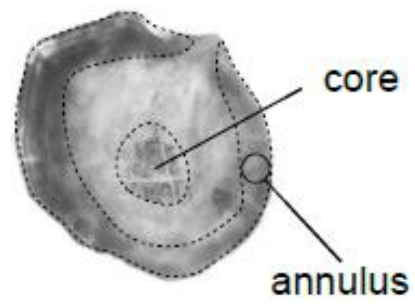

B. brevirostris

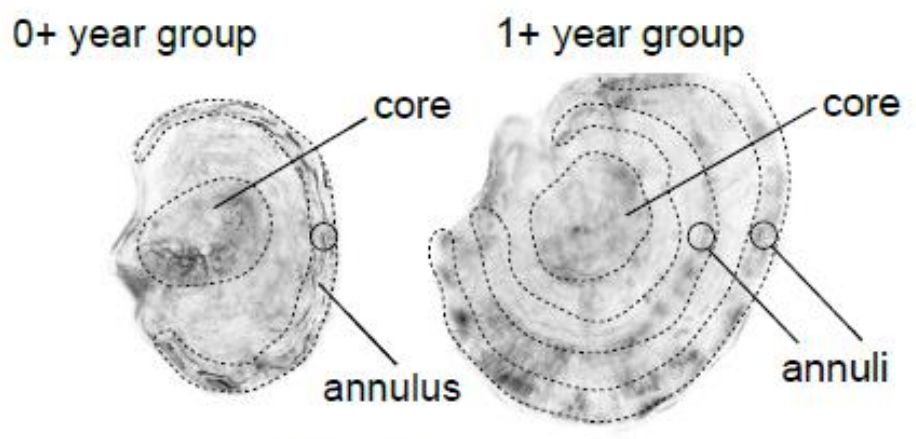

B. flavipomus

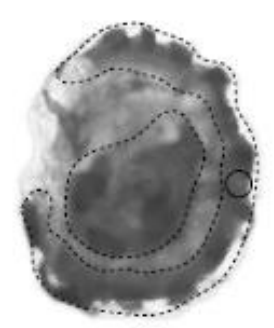

B. regani

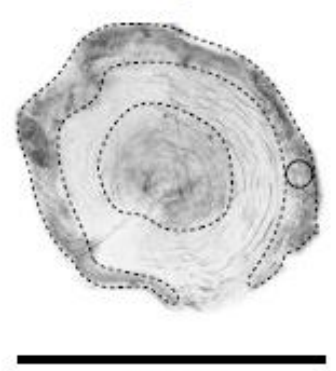

$1 \mathrm{~mm}$ 